\title{
Chimeric antigen receptor-modified $T$ cells for the immunotherapy of patients with EGFR-expressing advanced relapsed/refractory non-small cell lung cancer
}

\author{
Kaichao Feng ${ }^{1 \dagger}$, Yelei Guo ${ }^{2 \dagger}$, Hanren Dai ${ }^{2 \dagger}$, Yao Wang ${ }^{2}$, Xiang $\mathrm{Li}^{3}$, Hejin $\mathrm{Jia}^{1}$ \\ \& Weidong Han ${ }^{1,2,3^{*}}$ \\ ${ }^{1}$ Department of Bio-therapeutic, Institute of Basic Medicine, Chinese PLA General Hospital, Beijing 100853, China; \\ ${ }^{2}$ Department of Immunology, Institute of Basic Medicine, Chinese PLA General Hospital, Beijing 100853, China; \\ ${ }^{3}$ Department of Molecular Biology, Institute of Basic Medicine, Chinese PLA General Hospital, Beijing 100853, China
}

Received January 16, 2016; accepted February 1, 2016; published online March 10, 2016

\begin{abstract}
The successes achieved by chimeric antigen receptor-modified T (CAR-T) cells in hematological malignancies raised the possibility of their use in non-small lung cancer (NSCLC). In this phase I clinical study (NCT01869166), patients with epidermal growth factor receptor (EGFR)-positive ( $>50 \%$ expression), relapsed/refractory NSCLC received escalating doses of EGFR-targeted CAR-T cell infusions. The EGFR-targeted CAR-T cells were generated from peripheral blood after a 10 to 13-day in vitro expansion. Serum cytokines in peripheral blood and copy numbers of CAR-EGFR transgene in peripheral blood and in tissue biopsy were monitored periodically. Clinical responses were evaluated with RECIST1.1 and immune-related response criteria, and adverse events were graded with CTCAE 4.0. The EGFR-targeted CAR-T cell infusions were well-tolerated without severe toxicity. Of 11 evaluable patients, two patients obtained partial response and five had stable disease for two to eight months. The median dose of transfused $\mathrm{CAR}^{+} \mathrm{T}$ cells was $0.97 \times 10^{7}$ cells $\mathrm{kg}^{-1}$ (interquartile range (IQR), 0.45 to $1.09 \times 10^{7}$ cells $\mathrm{kg}^{-1}$ ). Pathological eradication of EGFR positive tumor cells after EGFR-targeted CAR-T cell treatment can be observed in tumor biopsies, along with the CAR-EGFR gene detected in tumor-infiltrating T cells in all four biopsied patients. The EGFR-targeted CAR-T cell therapy is safe and feasible for EGFR-positive advanced relapsed/refractory NSCLC.
\end{abstract}

chimeric antigen receptor, immunotherapy, epidermal growth factor receptor, relapsed/refractory, non-small cell lung cancer

Citation: $\quad$ Feng, K., Guo, Y., Dai, H., Wang, Yao., Li, X., Jia, H., and Han, W. (2016). Chimeric antigen receptor-modified T cells for the immunotherapy of patients with EGFR-expressing advanced relapsed/refractory non-small cell lung cancer. Sci China Life Sci 59, $468-479$. doi: $10.1007 / \mathrm{s} 11427-016-5023-8$

\section{INTRODUCTION}

Lung cancer, including non-small cell lung cancer (NSCLC), is a major cause of cancer-related deaths worldwide. In 2013, an estimated 159,480 patients died of lung

$\dagger$ Contributed equally to this work

*Corresponding author (email: hanwdrsw69@yahoo.com) cancer in the United States, which accounted for approximately $27 \%$ of all cancer-related deaths (American Cancer Society, 2013). The high mortality rate for patients with NSCLC is largely due to the fact that most patients are diagnosed with advanced stage disease or are resistant to standard treatments. The strategies for treating patients with advanced NSCLC include chemotherapy, targeted therapy and supporting care. A series of randomized trials have 
demonstrated that chemotherapy regimens provide a similar, modest level of efficacy in treating NSCLC (Azzoli et al., 2009; Bunn et al., 2002; D’Addario et al., 2009; Grossi et al., 2009; Scagliotti et al., 2008), while targeted therapeutic agents, such as Erlotinib and Gefitinib, improved the objective response rates in patients with EGFR mutation. However, the addition of chemotherapy to the targeted therapeutic agent regimen did not prolong the survival time (Gatzemeier et al., 2007; Giaccone et al., 2004; Herbst et al., 2004, 2005).

Since it was first introduced by Eshhar et al., chimeric antigen receptor (CAR) redirected $\mathrm{T}$ cell therapy has emerged as a promising strategy for treating malignancies (Eshhar et al., 1993). Unlike T cell receptors (TCRs), CARs are synthetic receptors containing an extracellular antigen recognition domain, a transmembrane domain and a cytoplasmic signaling domain. Therefore, CARs are capable of redirecting the specificity of $\mathrm{T}$ cells and NK cells to tumor-associated antigens (TAAs) expressed on the tumor cells by recognizing the targeted antigen in a major histocompatibility complex (MHC)-independent manner (Li et al., 2015). Today, most of the dramatic successes of CAR-based immunotherapy have been achieved in malignant hematological diseases, such as anti-CD19 CAR-T cells in treating acute lymphoblastic leukemia (ALL), chronic lymphocytic leukemia (CLL) and non-Hodgkin lymphomas (NHL) (Brentjens et al., 2013; Grupp et al., 2013; Kochenderfer et al., 2012, 2015; Porter et al., 2011), as well as CD20-specific CAR-T cells in treating NHL (Till et al., 2008, 2012). However, there are few studies with regard to solid tumors, particularly with regard to NSCLC.

Epidermal growth factor receptor (EGFR), also known as human epidermal receptor 1 (Her-1), is a transmembrane glycoprotein that is expressed in both epithelial cells and many epithelium-derived malignancies. EGFR overexpression results in gene amplification and mutation, which affects cell proliferation, survival, metastasis and tumorinduced neoangiogenesis (Ciardiello et al., 2008). Compared to normal lung tissues, the significant elevation of low- and high-affinity of binding sites in lung carcinomas makes EGFR a promising therapeutic target (Salomon et al., 1995). Therefore, we select EGFR as the target for adoptive $\mathrm{T}$ cells expressing CARs to investigate the safety, feasibility and activity of CAR-T cell therapy in patients with advanced relapsed/refractory NSCLC.

\section{RESULTS}

\section{Patients characteristics}

Six female patients and five male patients with advanced relapsed/refractory NSCLC were enrolled in this study (Table 1). The median age of the patients was 58 years (range 40-66 years). The grade of EGFR expression determined by the immunohistochemistry (IHC) method were at least $50 \%$ (Table S1 in Supporting Information). The ratio of adeno- carcinoma to squamous cell carcinoma was 8:3. All patients had at least one relapsed/metastatic or therapeutic-resistant lesion. We defined therapeutic resistance as no achievement of at least a partial remission (PR) within the latest treatment cycle before enrolling into the anti-EGFR CAR protocol. In cohort 1 , four patients were administered CAR-T-EGFR therapy without any conditioning regimens. In cohort 2, two patients were conditioned with cyclophosphamide alone prior to CAR-T-EGFR cell infusion. In cohort 3, two patients were administered cyclophosphamide, pemetrexed $\left(500 \mathrm{mg} \mathrm{m}^{-2}\right)$ and cisplatin $\left(75 \mathrm{mg} \mathrm{m}^{-2}\right)$, and three patients were administered cyclophosphamide, docetaxel $\left(75 \mathrm{mg} \mathrm{m}^{-2}\right)$ and cisplatin $\left(75 \mathrm{mg} \mathrm{m}^{-2}\right)$.

\section{Generation, characteristics and specific cytotoxicity of patient-derived anti-EGFR CAR-T cells}

After culturing for 10 to 13 days, the CAR-T-EGFR cell products were successfully generated for all patients and released for infusion (Figure 1B). The population of CAR-T-EGFR cells contained a mean of $93.72 \%$ of $\mathrm{CD}^{+}$ T, with mean CD4:CD8 percentage of 26.72:66.97 (Table $\mathrm{S} 2$ in Supporting Information). Furthermore, more than $16 \%$ of CAR-T-EGFR cell population was central memory cells $\left(\mathrm{CD} 45 \mathrm{RO}^{+} \mathrm{CCR} 7^{+} \mathrm{CD}^{2} 2 \mathrm{~L}^{+}\right)$, whereas $30.72 \%$ of these cells were effector memory cells $\left(\mathrm{CD} 45 \mathrm{RO}^{+} \mathrm{CCR} 7^{-} \mathrm{CD}^{2} \mathrm{~L}^{-}\right.$) (Table S2 in Supporting Information). In total, a median of $29.28 \%$ (IQR, $20.87 \%$ to $31.22 \%$ ) of T cells were expressed the CAR as tested by flow cytometry analysis (Figure S1 in Supporting Information). The specific cytotoxicity of the CAR-T-EGFR cells was observed after co-incubation with the $\mathrm{EGFR}^{+}$cell line A549, MCF7 and HeLa (Figure 1C), which demonstrated that these cells from patients possessed specific cytolytic activity against EGFR-positive tumor cells. The CAR-T-EGFR cells produced cytokines in an EGFR-specific manner (Figure 1D). The CAR-T-EGFR cells produced high levels of interferon (IFN)-gamma, tumor necrosis factor (TNF)-alpha, interleukin (IL)-2, IL-4, IL-6, granulocyte-macrophage colony-stimulating factor (GM- CSF) and Granzyme B when they were co-cultured with EGFR overexpressing tumor cells, whereas no significant elevation of cytokines secretion were observed when the CAR-T-EGFR cells were co-cultured with EGFRnegative tumor cells.

\section{The persistence of CAR-T-EGFR cells in the peripheral blood and tumors}

The persistence of CAR-expressing $\mathrm{T}$ cells in the peripheral blood was measured by quantitative real-time PCR (Q-PCR). This was used to analyze the genomic DNA from the patients' peripheral blood that was collected at serial time points to determine the persistence of these cells in vivo (Figure 2A). The CAR-T-EGFR cells were detectable for 11 to 34 days in patients 2, 5, 9 and 10. In contrast, the CAR-T-EGFR cells were sustainable for seven to 37 weeks 
Table 1 Patient cinical caracteristics ${ }^{\text {a) }}$

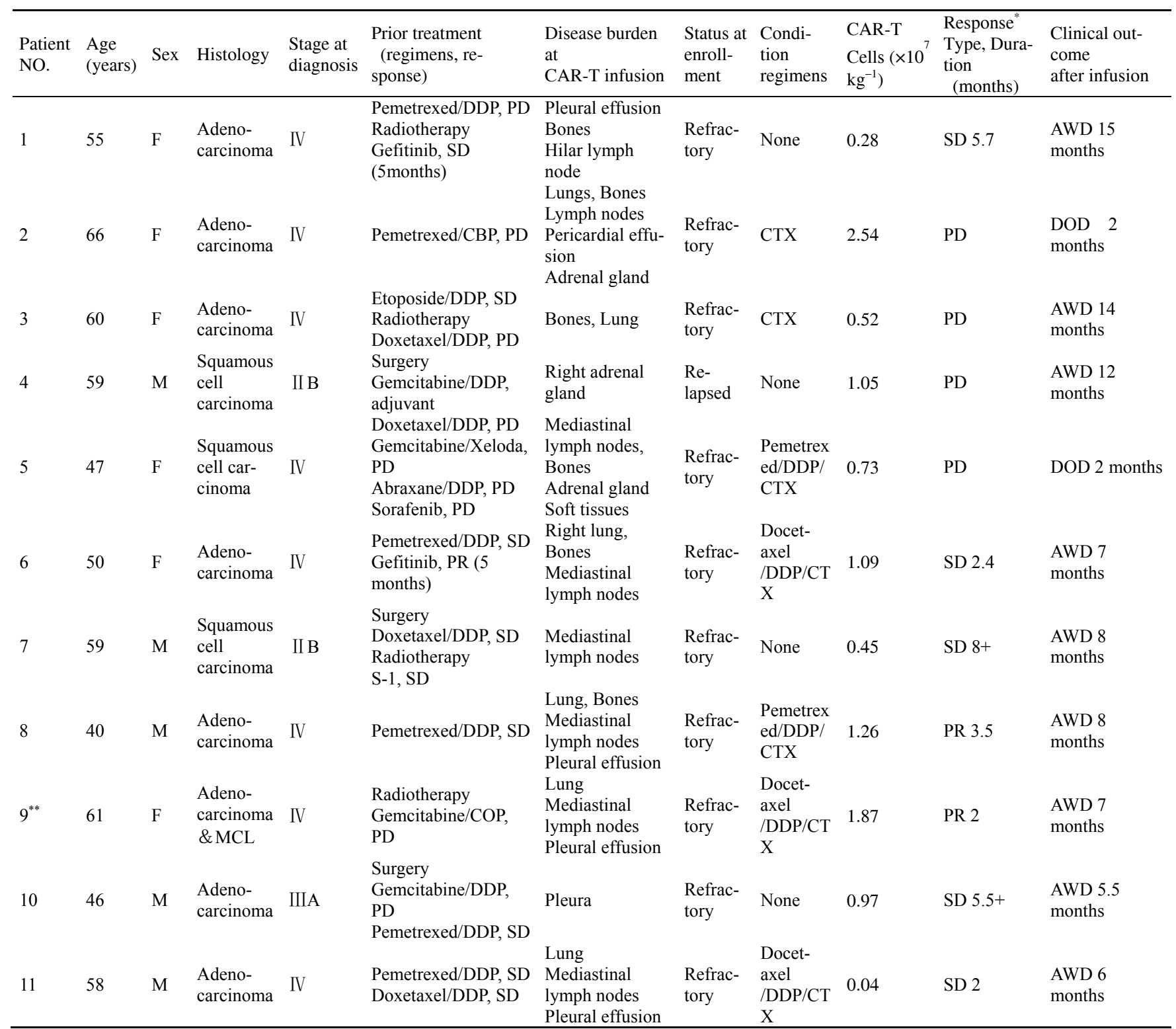

a) PR, partial response. SD, stable disease. $\mathrm{PD}$, progressive disease. DDP, cisplatin. CBP, carboplatin. CTX, cyclophosphamide. AWD, alive with disease. DOD, died of disease. *, Response duration is time from first documentation of response post CAR-EGFR T cells infusion until progression. **, Patient 9, having a history of mantle cell lymphoma (MCL), was diagnosed as right lung adenocarcinoma one year ago and PET/CT identified the relapse of MCL meanwhile. Considering the co-existence of lung cancer and MCL, she was administrated with chemotherapy regimens consisted of gemcitabine, cyclophosphamide, vindesine and prednisone (COP), which could be effective to both malignancies.

in the other seven patients. CAR copy numbers in peripheral blood maintained a high level (>1,000 copies $\left.\mathrm{mg}^{-1} \mathrm{gDNA}\right)$ for more than four weeks in patients $1,2,3,6,7,9$ and 10 .

In order to demonstrate whether the CAR-T-EGFR cells could effectively traffic into the tumor tissues, the level of CAR-T-EGFR cells was also determined in the biopsied tumor tissues by Q-PCR. Four out of 11 patients received tumor biopsy by fine needle aspiration (FNA) after the anti-EGFR CAR-T cell infusion. Among these four, patients 1 and 8 had newly emerged metastatic lymph nodes in the left supraclavicular fossa with the short axis larger than $15 \mathrm{~mm}$. Meanwhile, the level of CAR-T-EGFR cells infiltrating into the tumor tissues was measured in patients 2, 6 and 8 (Figure 2B). Compared with the level of CAR-T-EGFR cells in the peripheral blood of patient 1 at 26 weeks, patient 2 at six weeks, patient 8 at six and 16 weeks, respectively, CAR-T cells could specifically accumulate in the tumor tissues (Figure 2B).

\section{Safety of CAR-T-EGFR cells}

The most common adverse occurences for the patients after CAR-T cell infusion were mild skin toxicity, nausea, vomiting, dyspnea and hypotension (Table 2). One patient suffered a transient grade 3-4 increase in serum lipase. The 
A

Anti-EGFR scFv
\begin{tabular}{|c|c|c|c|c|}
\hline$V_{L}$ & $V_{H}$ & $\begin{array}{c}\text { CD8a hinge } \\
\text { and TM }\end{array}$ & CD137 & CD3zeta \\
\hline
\end{tabular}

B
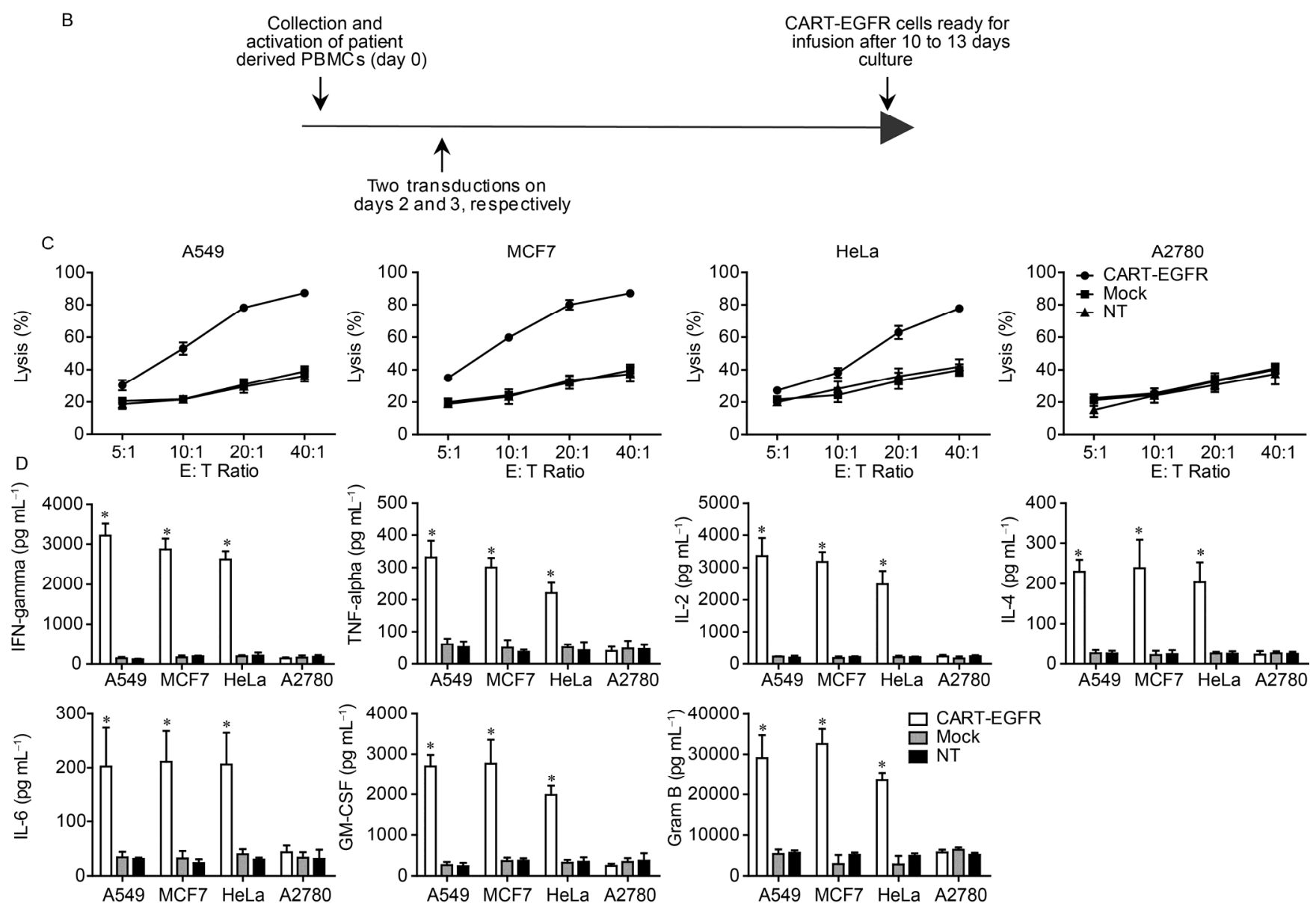

Figure 1 General characteristics of CAR-T-EGFR cells. A, Schematic representation of anti-EGFR CAR, not to scale. CAR contained anti-EGFR scFv, CD8a hinge and transmembrane region, CD137 costimulatory domain and CD3zeta T-cell activation domain. B, The CAR-T-EGFR cell products were produced by activated peripheral blood mononuclear cells (PBMCs) and released for infusion after 10 to 13 days in culture. C, Specific cytotoxicity of CAR-T-EGFR cells to the EGFR-expressing tumor cells. Results of a $4 \mathrm{~h}$ CCK8 analysis at effector/tumor cell (E:T) ratio of 5:1, 10:1, 20:1 and 40:1. The effector cells were CAR-T-EGFR, mock and NT cells. The target cells were A549 (EGFR ${ }^{+}$) human lung carcinoma cell line, MCF7 (EGFR ${ }^{+}$) human breast carcinoma cell line, HeLa (EGFR ${ }^{+}$) human cervical carcinoma cell line, and A2780 (EGFR ${ }^{-}$) human ovarian cancer cell line. The EGFR expression in these tumor cells was detected by flow cytometry (Figure S2 in Supporting Information). Results are representative of all patients' $\mathrm{T}$ cell products as means \pm SD (CAR-T-EGFR versus Mock and NT, $P<0.001$, two-way ANOVA test, GraphPad Prism 6.0). NT indicates non-viral transduction T cells. D, ELISA assay showing the level of cytokines, including IL-2, IL-4, IL-6, TNF-alpha, IFN-gamma, GM-CSF and Gram B, in supernatants from CAR-T-EGFR cells co-cultured with A549, MCF7, HeLa or A2780 cells at an E:T ratio of 20:1 for $24 \mathrm{~h}$. Results are representative of all patients' T cell products as means \pm SD (*, $P<0.001$ versus Mock and NT, two-way ANOVA test, GraphPad Prism 6.0).

Table 2 Adverse events graded according to national cancer institute common terminology criteria for adverse events version 4.0

\begin{tabular}{cccccc}
\hline \multirow{2}{*}{ Adverse events } & \multicolumn{2}{c}{ Grade 1-2 } & & \multicolumn{2}{c}{ Grade 3-4 } \\
\cline { 2 - 3 } \cline { 5 - 6 } & No. of patients & $\%$ & & No. of patients & $\%$ \\
\hline Rash/Acne/Dry Skin & 2 & 18.2 & & 0 & 0 \\
Nausea & 1 & 9.1 & & 0 & 0 \\
Vomiting & 1 & 9.1 & & 0 & 0 \\
Dyspnea & 4 & 36.4 & & 0 & 0 \\
Hypotension & 1 & 9.1 & & 0 & 0 \\
Serum amylase elevation & 1 & 9.1 & & 0 & 0 \\
Serum lipase elevation & 0 & 0 & & 1 & 9.1 \\
\hline
\end{tabular}

level of patients' plasma cytokines, including IL-2, IL-4, IL-6, IL-8, IL-10, IL-12p70, IL-12/IL23p40, IFN-gamma, TNF-alpha, VEGF and Granzyme B, were analyzed at serial time points before and after the CAR-T-EGFR cell infusion (Figure S3 in Supporting Information). Obvious fluctuation of these cytokines was not observed in all patients after the infusion of EGFR-specific CAR-T cells during the follow-up period.

\section{Clinical response}

The median dose of transfused $\mathrm{CAR}^{+} \mathrm{T}$ cells was $0.97 \times 10^{7}$ cells $\mathrm{kg}^{-1}$ (IQR, 0.45 to $1.09 \times 10^{7}$ cells $\mathrm{kg}^{-1}$ ). Two patients 

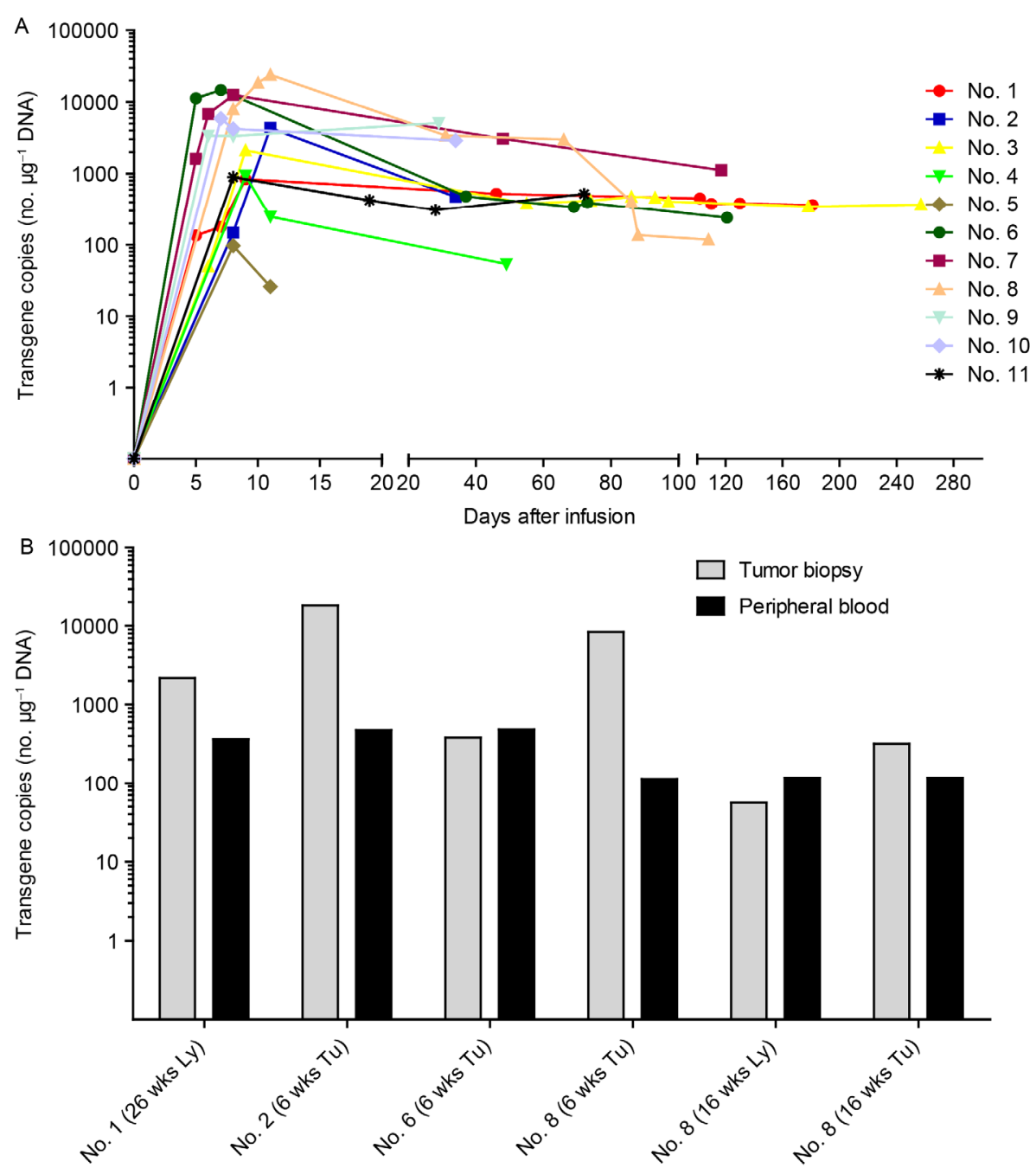

Figure 2 In vivo persistence of CAR-T-EGFR cells. A, The persistence of the infused CAR-T-EGFR cells in the peripheral blood. Q-PCR was used to assess the level of CAR-T-EGFR cells using the DNA obtained from the PBMCs of all patients, which were harvested before and at serial time points after CAR-T-EGFR cell infusion. B, Correlations of the CAR copy numbers in tumor biopsy versus peripheral blood collected at the same time. Q-PCR analyses showing the levels of CAR-T-EGFR cells using the DNA obtained from ultrasound-guided biopsy of malignant lymph nodes or tumor tissues. Malignant lymph nodes were separately collected at 26 weeks in patient 1 and at 16 weeks in patient 8 after CAR-T-EGFR cell infusion. Tumor tissues in the lung were separately collected at six weeks in patient 2, at six weeks in patient 6 and at 6 weeks and 16 weeks in patient 8 after CAR-T cell infusion. Ly indicates malignant lymph node, and Tu indicates tumor tissue from the lung.

obtained PR and five had stable diseases (SD) after the infusion of CAR-T-EGFR cells (Table 1). In cohort 1, three patients obtained SD and one patient progressed. With the exception of two SD patients, two patients in cohort 3 also had a PR. In contrast, the outcome of the patients conditioned with cyclophosphamide alone was poor. The disease of one patient progressed quickly with multiple new metastatic lesions in the liver, lungs and bones, as well as rapid development of the primary lesion within one month, and this patient died of gastrointestinal hemorrhage two months later (the most likely cause of death was due to overdose of oral analgesics). The other patient had a new metastatic neoplasm detected next to her pancreas 1.8 months after the infusion of CAR-T cells.

Patient 1 was diagnosed with a stage IV lung adenocarcinoma with an EGFR exon 19 mutation. She was treated with one cycle of pemetrexed, cisplatin and radiotherapy for bone metastasis, followed by gefitinib for five months. She was recruited onto the CAR-T-EGFR protocol when gefitinib resistance was confirmed, and obtained a 5.7-month $\mathrm{SD}$ accompanied by reduction of pleural effusion (Figure $3 \mathrm{~A})$. The enrichment of $\mathrm{CD}^{+}$cells and reduction of EGFR-positive tumor cells were observed in the tumor tissue biopsied from the same metastatic lymph node in the supraclavicular fossa (Figure 4A).

Patient 6 had stage IV lung adenocarcinoma with an exon 19 deletion in EGFR. This patient presented with metastasis in the mediastinal lymph nodes, bones and left adrenal gland. She was previously treated with two cycles of first-line chemotherapy, which resulted in SD. Next, she was administered gefitinib, leading to PR that was maintained for five months. She was then treated with the 

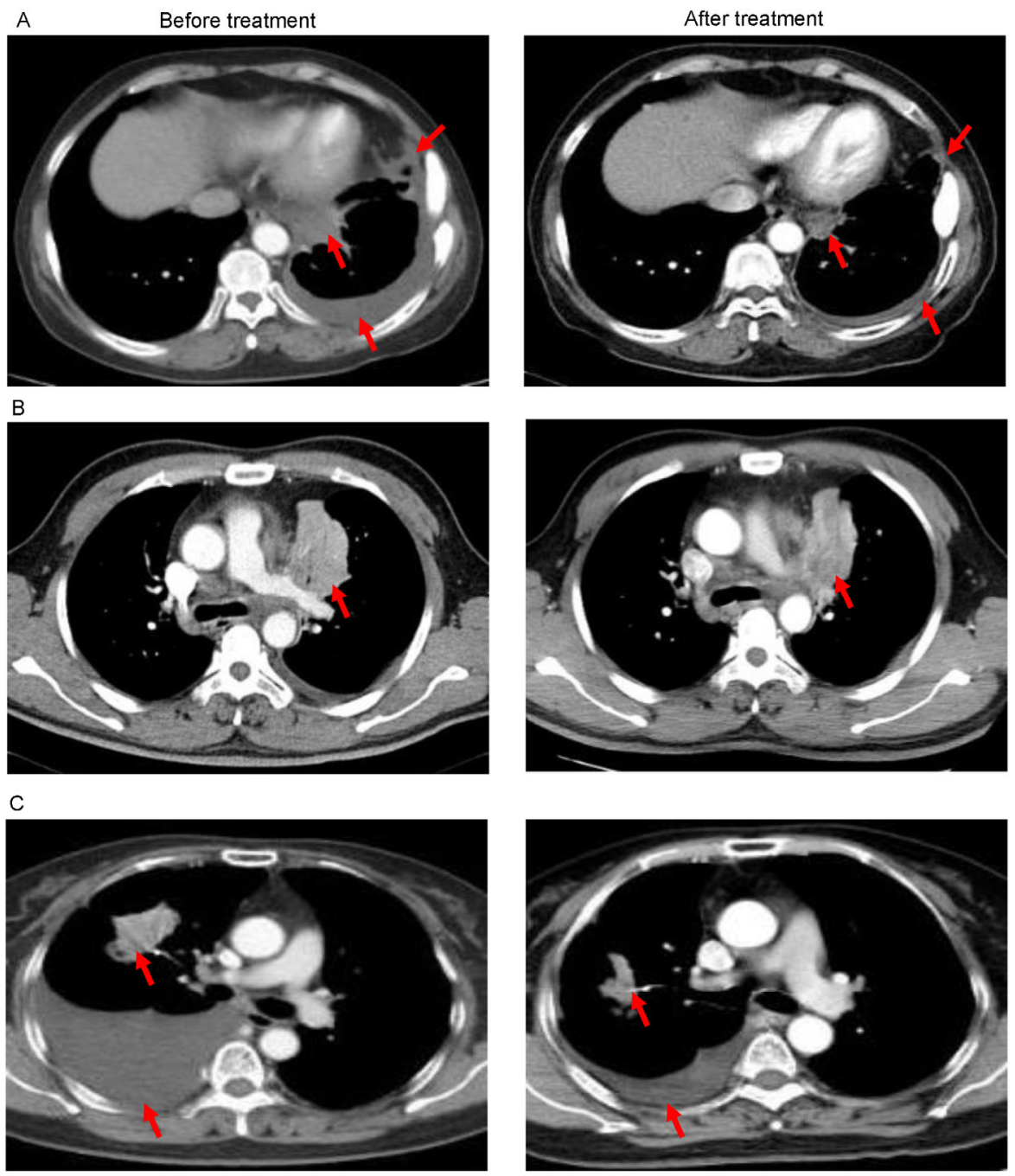

Figure 3 (color online) Outcome of anti-EGFR CAR-T cell infusion. A, Reduction of pleural effusion and slight shrinkage of metastatic hilar lymph node and pleural nodule in patient 1 were presented by computed tomography (CT) scans after the infusion of CAR-T cell (arrow). B, CT images showed the shrinkage of primary tumor in patient 8 (arrow). C, CT examination found the absorption of pleural effusion and remarkable regression of lung lesion in patient 9 after CAR-T treatment.

CAR-T-EGFR protocol when her tumor re-enlarged, and the result was SD. Interestingly, however, CT images showed enlargement of her lung cancer, immunohistochemical staining of the biopsied tissue from the same lung lesion pre- and post-treatment presented a dramatic clearance of EGFR-positive tumor cells and a rapid proliferation of EGFR-negative tumor cells (Figure 4B).

Patient 8 was treated with two cycles of first-line chemotherapy regimens after being diagnosed with a stage IV lung adenocarcinoma, which led to a transient SD. After confirmation of chemotherapy resistance, this patient received the anti-EGFR CAR-T cell infusion and entered a PR with shrinkage of the primary lesion, reduction of pleural effusion, and relief of cancer-related pain (Figure 3B). His PR status was maintained for 3.5 months until a new metastatic lymph node emerged in his left supraclavicular fossa and the primary lesion progressed again. The primary lesion was biopsied one month after the infusion of CAR-T cells, and at 3.5 months when progression was confirmed, along with the biopsy of the new metastatic lymph node. The successive IHC examinations showed a decrease of EGFR-positive tumor cells and an increase of EGFRnegative tumor cells in his lung lesion (Figure 4C).

Patient 9, having a history of mantle cell lymphoma (MCL), was once considered to have recurring MCL when a new lesion emerged in her right pulmonary lobe during her routine follow up. She received radiotherapy and four cycles of chemotherapy after being diagnosed with lung adenocarcinoma by FNA. However, her disease progressed with a $50 \%$ increase of the tumor lesion in right pulmonary lobe and appearance of massive pleural effusion when evaluated one month after the last cycle chemotherapy was completed. After treatment with the CAR-T-EGFR protocol, she entered a PR with shrinkage of both target neo- 

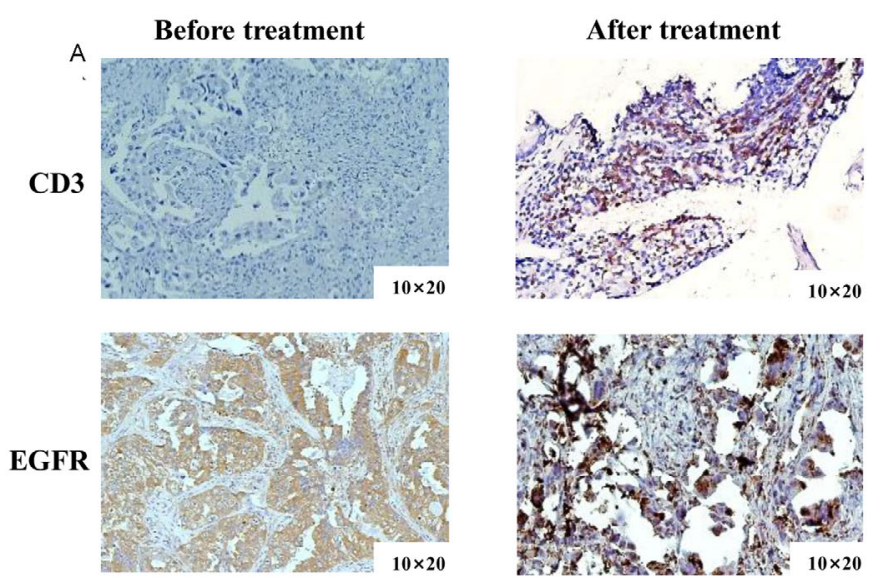

B
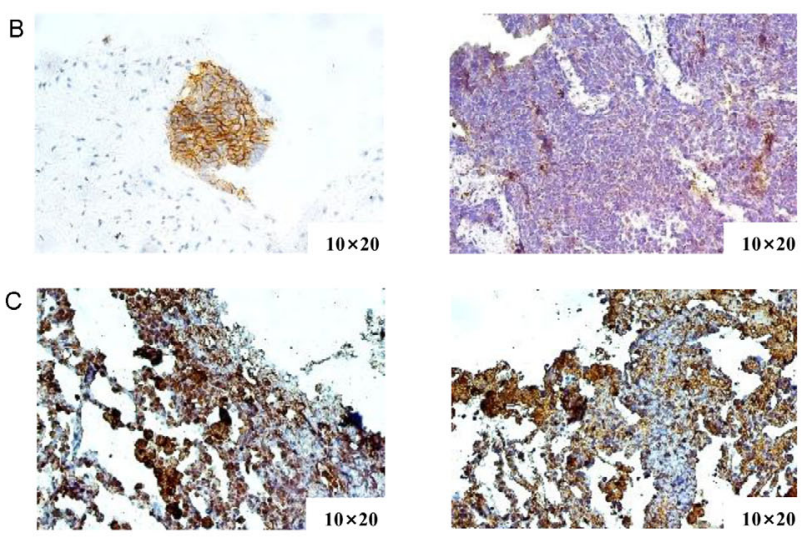

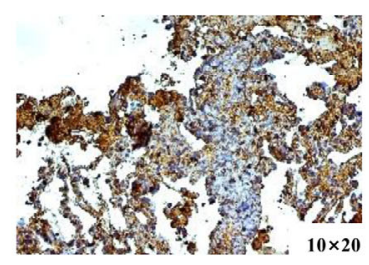

1 month after infusion

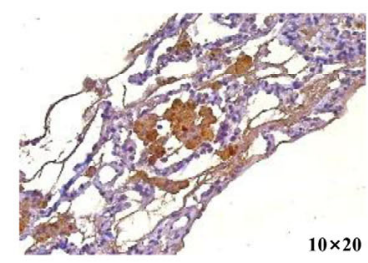

3.5 months after infusion

Figure 4 Immunohistochemistry examination of tumor tissues after the infusion of CAR-T cells. A, Biopsied tissue obtained from patient 1 at the supraclavicular lymph node metastasis showed the enrichment of $\mathrm{CD}^{+}$cells and reduction of EGFR ${ }^{+}$tumor cells, suggesting that the anti-EGFR CAR-T cells could traffic into the tumor tissues and might be related to the eradication of EGFR-expressing tumor cells. B, Patient 6 was biopsied at the same lesion in right lung one month after CAR-T cell infusion with a result of disappearance of EGFR expressing tumor cells and blast of cells without EGFR expression. C, Patient 8 was sampled one month and 3.5 months after the infusion of anti-EGFR CAR-T cells, immunohistochemistry examination of the biopsied tumor tissue presented a continuous reduction of EGFR positive tumor cells.

plasm and pleural effusion (Figure 3C). Unfortunately, because the deeper location of the target lesion in her right pulmonary lobe made it very dangerous to biopsy, there was no pathological evidence to furtherly assess the anti-EGFR CAR-T cell immunotherapy.

\section{DISCUSSION}

To our knowledge, this clinical trial was the first to study the safety and feasibility of CAR redirected autologous $\mathrm{T}$ cells for the immunotherapy of patients with advanced NSCLC. The mild toxicities which occurred in this study indicated that the infusion of CAR-T-EGFR cell was safe, and the clinical response including two PR suggested the feasibility and potential activity of the CAR-T-EGFR protocol. The pathological outcome from patient 1 indicated that the CAR-EGFR T cells could traffic into the tumor tissues and might be related to the eradication of EGFR-expressing tumor cells.

Following the success of in vitro expanded tumor- infiltrating lymphocytes (TILs) after a lymphodepleting regimen for the treatment of metastatic melanoma, we realized that the host's immune system needs to be properly conditioned prior to the infusion of adoptive immune cells to create an appropriate "lymphoid space" that is devoid of regulatory mechanisms (Dudley et al., 2002). The proper conditioning could enable the host to accommodate the transferred $\mathrm{T}$ lymphocytes and give these cells an advantage over other competing cell populations. Cyclophosphamide has historically been used to augment the antitumor immune responses before cell-based immunotherapy by depleting $\mathrm{CD} 4{ }^{+} \mathrm{CD} 25^{+}$regulatory $\mathrm{T}$ cells (Tregs) (Muranski et al., 2006). However, the poor outcome in cohort 2 indicates that conditioning with cyclophosphamide alone in solid tumors seems inappropriate. This is because the cyclophosphamide-mediated depletion of Tregs is usually transient and a new Treg cell population quickly re-forms (Alizadeh et al., 2014). In addition, the non-selective elimination or inhibition of effector $\mathrm{T}$ cells may contribute to tumor cells escaping from the host's immune surveillance and acceler- 
ating metastasis. Although many chemotherapeutic agents, such as pemetrexed and docetaxel (Anraku et al., 2010; Garnett et al., 2008), are generally referred to be cytotoxic, they can enhance immunity by reducing myeloid-derived suppressor cell (MDSC) infiltration, repair Tregs function or modulate $\mathrm{CD}^{+} \mathrm{T}$ cells (Kershaw et al., 2013). Moreover, chemotherapy could convert the tumor microenvironment into a highly permissive state for immune cells (Kang et al., 2013). Therefore, we suggest that patients with lesions larger than $3 \mathrm{~cm}$ should be conditioned with a combination of chemotherapeutic drugs and cyclophosphamide.

Current data, such as that of the milder toxicities experienced by patients in this protocol and no cytokine storm, indicated that the CAR-T-EGFR protocol was safe for the treatment of patients suffering advanced EGFR-positive NSCLC. We proposed interpretations in the following aspects. First, the safety of CAR-EGFR T cell was demonstrated in an animal model by Zhou et al. who reported that CAR modified EGFR-specific T lymphocytes have no, or only minimal, systemic acute toxicity in mice (Zhou et al., 2013). Second, the levels of transfused cells were safe when compared with the other trials that used CAR-T cells in patients with solid tumors (Ahmed et al., 2015; Louis et al., 2011; Robbins et al., 2011). Third, and more importantly, CAR-T-EGFR cells were successively infused with dose escalation.

On-target/off-tumor toxicity related to CAR-T cell infusion was proposed to have a lethal risk for solid tumor patients, given that the selected target antigens are not always restricted to tumor cells (Morgan et al., 2010). EGFR expression has been observed in both epithelium-derived malignancies and most epithelial cells, raising great concerns in the target-mediated toxicity on EGFR-expressing normal tissues. However, the lower affinity of CAR molecule with EGFR antigen may discriminate the damage activities between normal cells with relatively lower level expression of EGFR and tumors with higher expression (Caruso et al., 2015; Chmielewski et al., 2014; Liu et al., 2015). In this study, tolerable and controllable EGFR targeting-related toxicities were just observed in 11 NSCLC cases as shown in Table 2, implying an appropriate affinity of EGFR-CAR epitope we adopted.

Interestingly, the current study showed that EGFR exon 19 deleted-patients who failed to respond to EGFR tyrosine kinase inhibitors (EGFR-TKI) could reach a better outcome after the infusion of CAR-T-EGFR cells. This implied that the CAR-T-EGFR cell immunotherapy may be more effective in the presence of a secondary mutation of EGFR. The T790 M mutation, which occurred in approximately 50\% of patients with EGFR-TKI resistance, was the most common secondary mutation (Oxnard et al., 2011), and was reported to be capable of transforming $\mathrm{T}$ cell epitopes, which in turn could result in sensitization of EGFR antigen to antibodies (Yamada et al., 2013).

To our knowledge, the trafficking of effector $\mathrm{T}$ cells to the tumor is a prerequisite for $\mathrm{T}$ cells to carry out their anti-tumor effects (Robbins et al., 2004). In this trial, we monitored the level of CAR-T-EGFR cells in the peripheral blood and biopsied tumor tissues by Q-PCR. The results showed that copies of the CAR gene could be detected in primary lesions and metastatic sites, indicating that the CAR-T-EGFR cells could effectively migrate into the tumor lesions. However, our data also revealed that the amounts of CAR-T-EGFR cells in peripheral blood were not paralleled to that in tumor lesions or the clinical outcomes, implying that the level of CAR-T-EGFR cells in peripheral blood was not likely to be a valid index for monitoring the effect of CAR-T-EGFR cells in solid tumors.

In conclusion, our data demonstrate that the CAR-TEGFR protocol is safe and feasible for treating EGFRpositive advanced relapsed/refractory NSCLC, suggesting that the CAR-T cell therapy could be a promising anticancer strategy for other solid tumors, particularly those with high EGFR expression. Improvements of the CAR vector, transfection efficiency, $\mathrm{T}$ cell culture and conditioning regimens may further improve the activity of CAR-T-EGFR protocol. Meanwhile, we lack a more proper index that could reflect the function of CAR-T-EGFR cells in vivo and valid methods for managing EGFR-negative tumor cells after the anti-EGFR CAR-T cell therapy. This urgently needs to be resolved in the near future.

\section{MATERIALS AND METHODS}

\section{Study design}

This study was an open-label, prospective phase I trial (registered at www.clinicaltrials.gov as NCT01869166) conducted on patients with $\mathrm{EGFR}^{+}$advanced relapsed/refractory NSCLC who failed to respond to the standard chemotherapies or EGFR tyrosine kinase inhibitors. Eleven patients were recruited between July 1, 2013, and November 30,2014 . The primary objective was to evaluate the safety and feasibility of CAR-T-EGFR protocol in treating patients suffering EGFR positive advanced NSCLC. The secondary objective was to assess the efficacy of CAR-expressing $\mathrm{T}$ cells.

\section{Eligibility criteria}

Eligible patients were aged 18 years or older, had histologically confirmed NSCLC with EGFR expression, had an Eastern Cooperative Oncology Group performance status of 0-2, had measurable lesions, had received at least two cycles of chemotherapy or targeted therapy with poor outcomes, and had provided written informed consent. The Ethics Committees of the Chinese PLA General Hospital approved the study protocol.

\section{Construction of the chimeric antigen receptor and lenti- virus production}

The EGFR-binding single chain fragment variable (scFv) 
sequence was derived from GenBank No. JQ306330.1. The anti-EGFR scFv-CD137-CD3zeta CAR (Figure 1A) was generated and cloned into the lentiviral backbone pWPT, which consisted of a Kozak sequence, a signal peptide of rat growth hormone, a $\mathrm{V}_{\mathrm{L}}$ region sequence of the anti-human EGFR antibody, a linker peptide, a $V_{H}$ region sequence of the anti-human EGFR antibody, the human CD8a molecule transmembrane region, and intracellular signaling domains of CD137 and CD3zeta. The construct was verified by sequencing. A pseudotyped, clinical-grade anti-EGFR CARencoding lentiviral vector was manufactured by standard transient transfection of a three-plasmid system into 293T cells as previously described (McGinley et al., 2011). The pWPT-anti-EGFR CAR plasmid, ps-PAX2 packaging plasmid and pMD2.G envelope plasmid were transfected into 293T cells using the PEI transfection reagent (Sigma-Aldrich, USA), according to the manufacturer's instructions. The lentiviral supernatants were collected and stored at $-80^{\circ} \mathrm{C}$.

\section{Anti-EGFR CAR-T cells}

The patients' CAR-T-EGFR cells were manufactured at the Chinese PLA General Hospital Good Manufacturing Practice facility using standard operating procedures. Peripheral blood mononuclear cells (PBMCs), collected by Ficoll-Hypaque density-gradient centrifugation, were cultured on plates coated with $5 \mu \mathrm{g} \mathrm{mL}^{-1}$ anti-CD3 MoAb (TaKaRa, Japan) in GT-T551 medium (TaKaRa) supplemented with $1,000 \mathrm{U} \mathrm{mL}^{-1}$ recombinant human IL-2 (rhIL-2) (Peprotech, USA). On day two of cell culture, the culturing supernatants were removed and lentiviral transduction was performed in GT-T551 medium with protamine sulfate (Sigma) and 1,000 $\mathrm{U} \mathrm{mL}^{-1}$ rhIL-2 for $24 \mathrm{~h}$. A second transduction was performed on the following day. After transduction, CAR-T cells were transferred to culture bags (TaKaRa). Fresh medium containing $1,000 \mathrm{U} \mathrm{mL}^{-1}$ rhIL-2 was added every three days.

\section{Conditioning regimens and infusion of CAR-T-EGFR cells}

Based on the tumor burden, the enrolled patients were assigned to three different cohorts: in cohort 1 , patients who had tumor size less than $3 \mathrm{~cm}$ or who could not tolerate the toxicity of chemotherapy although the lesions were larger than $3 \mathrm{~cm}$ were not administered with any conditioning treatment. Patients in cohorts 2 and 3, who had tumors no less than $3 \mathrm{~cm}$, were conditioned with cyclophosphamide and combination of chemotherapy and cyclophosphamide, respectively. Chemotherapy was administered seven days prior to the anti-CAR-EGFR $\mathrm{T}$ cell infusion. Cyclophosphamide was administered at a dose of $30 \mathrm{mg} \mathrm{kg}^{-1}$ three days before the infusion of $\mathrm{T}$ cells. The CAR-T-EGFR cells were successively infused with dose escalation. rhIL-2 was administered in the following five days. The clinical re- sponses were defined according to RECIST1.1 and immune-related response criteria (Eisenhauer et al., 2009; Wolchok et al., 2009). Adverse events were documented and graded based upon the Common Terminology Criteria for Adverse Events Version 4.0 (CTCAE 4.0). Serum samples detecting CAR-T cells were collected on days 1,3 , and 5 and then every month after the infusion of the CAR-TEGFR cells.

\section{Follow-up}

At follow-up, patients were assessed monthly for measurable and non-measurable lesions using Computed Tomography, the number of transgene copies of the CAR vector in peripheral blood and/or lesions, and hematology and biochemistry until there was evidence of disease progression or death. The target lesions were biopsied to measure the number of CAR-T-EGFR cells that infiltrated the tumor tissues and to monitor any changes in EGFR expression on the tumor cells.

\section{Flow cytometry}

The surface expression of CAR-T-EGFR cell products was analyzed by flow cytometry. The CAR-T cells were collected after culturing 10 to 13 days and stained with anti-human antibodies against CD3-PerCP, CD4-FITC, CD8-PE, CD45RO-APC, CD56-APC, CD62L-PE and CCR7-PE- CY7 (BD Biosciences, USA) for $30 \mathrm{~min}$ at $4^{\circ} \mathrm{C}$ in the dark. Isotype-matched monoclonal antibodies (BD Biosciences) were used for control staining. CAR expression was assayed with biotinylated protein L (GeneScript, Piscataway) as previously described (Zheng et al., 2012). Data acquisition and analysis were performed by FACSCalibur flow cytometry (BD Biosciences).

\section{Cellular cytotoxicity and cytokine assays}

The cytotoxic activity of CAR-T-EGFR cells was assessed by targeting the EGFR-positive human lung carcinoma cell line A549, human breast carcinoma cell line MCF7, and human cervical carcinoma cell line HeLa, as well as the EGFR-negative human ovarian cancer cell line A2780 as previously described (Zhou et al., 2013; Wang et al., 2011). The CAR-T-EGFR cells were co-cultured with A549, MCF7, HeLa or A2780 tumor cells at an effector-to-target $(E: T)$ ratio of $5: 1,10: 1,20: 1$ and $40: 1$, respectively, for 4 h. Nonor mock-transduced cells served as controls. The cytotoxicity of CAR-T-EGFR cells was evaluated using a Cell Counting Kit (CCK)-8 Detection kit (DOJINDO, Japan). Specific lysis was calculated as follows: \% Lysis= (control group -experimental group)/control group $\times 100 \%$. The levels of cytokines, including IL-2, IL-4, IL-6, TNF-alpha, IFN-gamma, GM-CSF and Gram B, in the cultured supernatant were assessed by ELISA after the CAR-T-EGFR cells co-cultured with A549, MCF7, HeLa or A2780 cells at an E:T ratio of 20:1 for $24 \mathrm{~h}$. 


\section{Quantitative real-time PCR}

Q-PCR was used to assess the persistence of the CAR-T-EGFR cells according to a previously described protocol (Savoldo et al., 2001). The genomic DNA was extracted from the PBMCs collected before and at different time points after the CAR-T cell infusion using a QIAamp DNA Blood Mini Kit (Qiagen, Valencia). The DNA was amplified in triplicate with primers and TaqMan probes (Applied Biosystems, USA) specific for a 153-bp (base pair) fragment that contains portions of the CD8a chain and adjacent 4-1BB chain (the forward primer 5'-GGTCCTTCTCCTGTCACTGGTT-3' and reverse primer 5'-TCTTCTTCTTCTGGAAATCGGCAG-3') using the ABI PRISM 7900HT Sequence Detection System (Applied Biosystems). Q-PCR was also used to assess the CAR fusion gene in the tumor sites and malignant lymph node biopsies.

\section{Cytokine measurements}

BD Biosciences microbead sandwich immunoassay was used to test and analyze the levels of serum IL-2, IL-4, IL-6, IL-8, IL-10, IL-12p70, IL-12/IL23p40, IFN-gamma, TNF-alpha, VEGF and Granzyme B according to the manufacturer's instructions using a BD FACSCalibur flow cytometry before and at different time points after the CAR-T-EGFR cell infusion.

\section{Statistics}

Descriptive statistics were used to summarize the data in multiplex analyses. GraphPad Prism version 6.0 for Windows was used to perform the statistical analysis. The results are shown as the means \pm SDs. The statistical significance between groups was determined using two-way analysis of variance (ANOVA). $P<0.05$ were considered to be statistically significant.

Compliance and ethics The author(s) declare that they have no conflict of interest.

Acknowledgements This work was supported by the Science and Technology Planning Project of Beijing City (Z151100003915076), the National Natural Science Foundation of China (31270820, 81230061, 81472612, 81402566), the National Basic Science and Development Programme of China (2013BAI01B04), and the Nursery Innovation Fund (15KMM50).

Ahmed, N., Brawley, V.S., Hegde, M., Robertson, C., Ghazi, A., Gerken, C., Liu, E., Dakhova, O., Ashoori, A., Corder, A., Gray, T., Wu M.F., Liu, H., Hicks, J., Rainusso, N., Dotti, G., Mei, Z., Grilley, B., Gee A., Rooney, C.M., Brenner, M.K., Heslop, H.E., Wels, W.S., Wang, L.L., Anderson, P., and Gottschalk, S. (2015). Human epidermal growth factor receptor 2 (HER2)-specific chimeric antigen receptor-modified T cells for the immunotherapy of HER2-positive sarcoma. J Clin Oncol $33,1688-1696$.

Alizadeh, D., and Larmonier, N. (2014). Chemotherapeutic targeting of cancer-induced immunosuppressive cells. Cancer Res 74, 2663-2668.

American Cancer Society (2013). Cancer Facts \& Figures 2013 (Atlanta: American Cancer Society).

Anraku, M., Tagawa, T., Wu, L., Yun, Z., Keshavjee, S., Zhang, L., John- ston, M.R., and de Perrot, M. (2010). Synergistic antitumor effects of regulatory $\mathrm{T}$ cell blockade combined with pemetrexed in murine malignant mesothelioma. J Immunol 185, 956-966.

Azzoli, C.G., Baker, S. J., Temin, S., Pao, W., Aliff, T., Brahmer, J., Johnson, D.H., Laskin, J.L., Masters, G., Milton, D., Nordquist, L., Pfister, D.G., Piantadosi, S., Schiller, J.H., Smith, R., Smith, T.J., Strawn, J.R., Trent, D., Giaccone, G., and American Society of Clinical Oncology (2009). American society of clinical oncology clinical practice guideline update on chemotherapy for stage IV non-small-cell lung cancer. J Clin Oncol 27, 6251-6266.

Brentjens, R.J., Davila, M.L., Riviere, I., Park, J., Wang, X., Cowell, L.G., Bartido, S., Stefanski, J., Taylor, C., Olszewska, M., Borquez-Ojeda, O., Qu, J., Wasielewska, T., He, Q., Bernal, Y., Rijo, I.V., Hedvat, C., Kobos, R., Curran, K., Steinherz, P., Jurcic, J., Rosenblat, T., Maslak, P., Frattini, M., and Sadelain, M. (2013). CD19-Targeted T cells rapidly induce molecular remissions in adults with chemotherapy-refractory acute lymphoblastic leukemia. Sci Transl Med 5, 177ra38.

Bunn, P.J. (2002). Chemotherapy for advanced non-small-cell lung cancer: who, what, when, why? J Clin Oncol 20(18 Suppl), 23S-33S.

Caruso, H.G., Hurton, L.V., Najjar, A., Rushworth, D., Ang, S., Olivares, S., Mi, T., Switzer, K., Singh, H., Huls, H., Lee, D.A., Heimberger, A.B., Champlin, R.E., and Cooper, L.J. (2015). Tuning sensitivity of CAR to EGFR density limits recognition of normal tissue while maintaining potent antitumor activity. Cancer Res 75, 3505-3518.

Chmielewski, M., Hombach, A., Heuser, C., Adams, G.P., and Abken, H. (2014). T cell activation by antibody-like immunoreceptors: increase in affinity of the single-chain fragment domain above threshold does not increase $\mathrm{T}$ cell activation against antigen-positive target cells but decreases selectivity. J Immunol 173, 7647-7653.

Ciardiello, F., and Tortora, G. (2008). EGFR antagonists in cancer treatment. N Engl J Med 358, 1160-1174.

D'Addario, G., and Felip, E. (2009). Non-small-cell lung cancer: ESMO clinical recommendations for diagnosis, treatment and follow-up. Ann Oncol 20(4 Suppl), 68-70.

Dudley, M.E., Wunderlich, J.R., Robbins, P.F., Yang, J.C., Hwu, P., Schwartzentruber, D.J., Topalian, S.L., Sherry, R., Restifo, N.P., Hubicki, A.M., Robinson, M.R., Raffeld, M., Duray, P., Seipp, C.A., Rogers-Freezer, L., Morton, K.E., Mavroukakis, S.A., White, D.E., and Rosenberg, S.A. (2002). Cancer regression and autoimmunity in patients after clonal repopulation with antitumor lymphocytes. Science 298, 850-854.

Eisenhauer, E.A., Therasse, P., Bogaerts, J., Schwartz, L.H., Sargent, D., Ford, R., Dancey, J., Arbuck, S., Gwyther, S., Mooney, M., Rubinstein, L., Shankar, L., Dodd, L., Kaplan, R., Lacombe, D., and Verweij, J. (2009). New response evaluation criteria in solid tumors: revised RECIST guideline (version 1.1). Eur J Cancer 45, 228-247.

Eshhar, Z., Waks, T., Gross, G., and Schindler, D.G. (1993). Specific activation and targeting of cytotoxic lymphocytes through chimeric single chains consisting of antibody-binding domains and the gamma or zeta subunits of the immunoglobulin and T-cell receptors. Proc Natl Acad Sci USA 90, 720-724.

Garnett, C.T., Schlom, J., and Hodge, J.W. (2008). Combination of docetaxel and recombinant vaccine enhances $\mathrm{T}$-cell responses and antitumoractivity: effects of docetaxel on immune enhancement. Clin Cancer Res 14, 3536-3544.

Gatzemeier, U., Pluzanska, A., Szczesna, A., Kaukel, E., Roubec, J., De Rosa, F., Milanowski, J., Karnicka-Mlodkowski, H., Pesek, M., Serwatowski, P., Ramlau, R., Janaskova, T., Vansteenkiste, J., Strausz, J., Manikhas, G.M., and von Pawel, J. (2007). Phase III study of erlotinib in combination with cisplatin and gemcitabine in advanced non-small-cell lung cancer: the Tarceva Lung Cancer Investigation Trial. J Clin Oncol 25, 1545-1552.

Giaccone, G., Herbst, R.S., Manegold, C., Scagliotti, G., Rosell, R., Miller, V., Natale R.B., Schiller, J.H., von Pawel, J., Pluzanska, A., Gatzemeier, U., Grous, J., Ochs, J.S., Averbuch, S.D., Wolf, M.K., Rennie, P., Fandi, A., and Johnson, D.H. (2004). Gefitinib in combination with gemcitabine and cisplatin in advanced non-small-cell lung cancer: a 
phase III trial-INTACT 1. J Clin Oncol 22, 777-784.

Grossi, F., Aita, M., Defferrari, C., Rosetti, F., Brianti, A., Fasola, G., Vinante, O., Pronzato, P., and Pappagallo, G. (2009). Impact of third-generation drugs on the activity of first-line chemotherapy in advanced non-small cell lung cancer: a meta-analytical approach. Oncologist 14, 497-510.

Grupp, S.A., Kalos, M., Barrett, D., Aplenc, R., Porter, D.L., Rheingold, S.R., Teachey, D.T., Chew, A., Hauck, B., Wright, J.F., Milone, M.C., Levine, B.L., and June, C.H. (2013). Chimeric antigen receptor-modified T cells for acute lymphoid leukemia. N Engl J Med 368, 1509-1518.

Herbst, R.S., Giaccone, G., Schiller, J.H., Natale, R.B., Miller, V., Manegold, C., Scagliotti, G., Rosell R, Oliff, I., Reeves, J.A., Wolf, M.K., Krebs, A.D., Averbuch, S.D., Ochs, J.S., Grous, J., Fandi, A., and Johnson, D.H. (2004). Gefitinib in combination with paclitaxel and carboplatin in advanced non-small-cell lung cancer: a phase III trial-INTACT 2. J Clin Oncol 22, 785-794.

Herbst, R.S., Prager, D., Hermann, R., Fehrenbacher, L., Johnson, B.E., Sandler, A., Kris, M.G., Tran, H.T., Klein, P., Li, X., Ramies, D., Johnson, D.H., and Miller, V.A. (2005). TRIBUTE: a phase III trial of Erlotinib Hydrochloride (OSI-774) combined with carboplatin and paclitaxel chemotherapy in advanced non-small-cell lung cancer. J Clin Oncol 23, 5892-5899.

Kang, T.H., Mao, C.P., Lee, S.Y., Chen, A., Lee, J.H., Kim, T.W., Alvarez, R.D., Roden, R.B., Pardoll, D., Hung, C.F., and Wu, T.C. (2013). Chemotherapy acts as an adjuvant to convert the tumor microenvironment into a highly permissive state for vaccination-induced antitumor immunity. Cancer Res 73, 2493-2504.

Kershaw, M.H., Devaud, C., John, L.B., Westwood, J.A., and Darcy, P.K. (2013). Enhancing immunotherapy using chemotherapy and radiation to modify the tumor microenvironment. Oncoimmunology 2, e25962.

Kochenderfer, J.N., Dudley, M.E., Feldman, S.A., Wilson,W.H., Spaner, D.E., Maric, I., Stetler-Stevenson, M., Phan, G.Q., Hughes, M.S., Sherry, R.M., Yang, J.C., Kammula, U.S., Devillier, L., Carpenter, R., Nathan, D.A., Morgan, R.A., Laurencot, C., and Rosenberg, S.A. (2012). B-cell depletion and remissions of malignancy along with cytokine-associated toxicity in a clinical trial of anti-CD19 chimeric-antigen-receptor-transduced T cells. Blood 119, 2709-2720.

Kochenderfer, J.N., Dudley, M.E., Kassim, S.H., Somerville, R.P., Carpenter, R.O., Stetler-Stevenson, M., Yang, J.C., Phan, G.Q., Hughes, M.S., Sherry, R.M., Raffeld, M., Feldman, S., Lu, L., Li, Y.F., Ngo, L.T., Goy, A., Feldman, T., Spaner, D.E., Wang, M.L., Chen, C.C., Kranick, S.M., Nath, A., Nathan, D.A., Morton, K.E., Toomey, M.A., and Rosenberg, S.A. (2015). Chemotherapy-refractory diffuse large B-cell lymphoma and indolent B-cell malignancies can be effectively treated with autologous $\mathrm{T}$ cells expressing an anti-CD19 chimeric antigen receptor. J Clin Oncol 33, 540-549.

Li, Y., Yin, J., Li, T., Huang, S., Yan, H., Leavenworth, J., and Wang, X. (2015). NK cell-based cancer immunotherapy: from basic biology to clinical application. Sci China Life Sci 58, 1233-1245.

Liu, X., Jiang, S., Fang, C., Yang S., Olalere, D., Pequignot, E.C., Cogdill, A.P., Li, N., Ramones, M., Granda, B., Zhou, L., Loew, A., Young, R.M., June, C.H., and Zhao, Y. (2015). Affinity-tuned ErbB2 or EGFR chimeric antigen receptor $\mathrm{T}$ cells exhibit an increased therapeutic index against tumors in mice. Cancer Res 75, 3596-3607.

Louis, C.U., Savoldo, B., Dotti, G., Pule, M., Yvon, E., Myers, G.D., Rossig, C., Russell, H.V., Diouf, O., Liu, E., Liu, H., Wu, M.F., Gee, A.P., Mei, Z., Rooney, C.M., Heslop, H.E., and Brenner, M.K. (2011). Antitumor activity and long-term fate of chimeric antigen receptor-positive T cells in patients with neuroblastoma. Blood 118, 6050-6056.

McGinley, L., McMahon, J., Strappe, P., Barry, F., Murphy, M., O’Toole, D., O'Brien, T. (2011). Lentiviral vector mediated modification of mesenchymal stem cells \& enhanced survival in an in vitro model of ischaemia. Stem Cell Res Ther 2, 12.

Morgan, R.A., Yang, J.C., Kitano, M., Dudley, M.E., Laurencot, C.M., and Rosenberg, S.A. (2010). Case report of a serious adverse event follow- ing the administration of $\mathrm{T}$ cells transduced with a chimeric antigen receptor recognizing ERBB2. Mol Ther 18, 843-851.

Muranski, P., Bon,i A., Wrzesinski, C., Citrin, D.E., Rosenberg, S.A., Childs, R., and Restifo, N.P. (2006). Increased intensity lymphodepletion and adoptive immunotherapy-how far can we go? Nat Clin Pract Oncol 3, 668-681.

Oxnard, G.R., Arcila, M.E., Chmielecki, J., Ladanyi, M., Miller, V.A., and Pao, W. (2011). New strategies in overcoming acquired resistance to epidermal growth factor receptor tyrosine kinase inhibitorsin lung cancer. Clin Cancer Res 17, 5530-5537.

Porter, D.L., Levine, B.L., Kalos, M., Baqq, A., and June, C.H. (2011). Chimeric antigen receptor-modified $\mathrm{T}$ cells in chronic lymphoid leukemia. N Engl J Med 365, 725-733.

Robbins, P.F., Dudley, M.E., Wunderlich, J., El-Gamil, M., Li, Y.F., Zhou, J., Huang, J., Powell, D.J., and Rosenberg, S.A. (2004). Cutting edge: persistence of transferred lymphocyte clonotypes correlates with cancer regression in patients receiving cell transfer therapy. J Immun 173, 7125-7130.

Robbins, P.F., Morgan, R.A., Feldman, S.A., Yang, J.C., Sherry, RM., Dudley, M.E., Wunderlich, J.R., Nahvi, A.V., Helman, L.J., Mackall, C.L., Kammula, U.S., Hughes, M.S., Restifo, N.P., Raffeld, M., Lee, C.C., Levy, C.L., Li, Y.F., El-Gamil, M., Schwarz, S.L., Laurencot, C., and Rosenberg, S.A. (2011). Tumor regression in patients with metastatic synovial cell sarcoma and melanoma using genetically engineered lymphocytes reactive with NY-ESO-1. J Clin Oncol 29, 917-924.

Salomon, D.S., Brandt, R., Ciardiello, F., and Normanno, N. (1995). Epidermal growth factor related peptides and their receptors in human malignancies. Crit Rev Oncol Hematol 19, 183-232.

Savoldo, B., Ramos, C.A., Liu, E., Mims, M.P., Keating, M.J., Carrum, G., Kamble, R.T., Bollard, C.M., Gee, A.P., Mei, Z., Liu, H., Grilley, B., Rooney, C.M., Heslop, H.E., Brenner, M.K., and Dotti, G. (2001). CD28 costimulation improves expansion and persistence of chimeric antigen receptor-modified $\mathrm{T}$ cells in lymphoma patients. J Clin Invest 121, 1822-1826.

Scagliotti, G.V., Parikh, P., von Pawel, J., Biesma, B., Vansteenkiste, J., Manegold, C., Serwatowski, P., Gatzemeier, U., Digumarti, R., Zukin, M., Lee, J.S., Mellemgaard, A., Park, K., Patil, S., Rolski, J., Goksel, T., de Marinis, F., Simms, L., Sugarman, K.P., and Gandara, D. (2008). Phase III study comparing cisplatin plus gemcitabine with cisplatin plus pemetrexed in chemotherapy-naive patients with advanced-stage non-small cell lung cancer. J Clin Oncol 26, 3543-3551.

Till, B.G., Jensen, M.C., Wang, J., Chen, E.Y., Wood, B.L., Greisman, H.A., Qian, X., James, S.E., Raubitschek, A., Forman, S.J., Gopal, A.K., Pagel, J.M., Lindgren, C.G., Greenberg, P.D., Riddell, S.R., and Press, O.W. (2008). Adoptive immunotherapy for indolent non-Hodgkin lymphoma and mantle cell lymphoma using genetically modified autologous CD20-specific T cells. Blood 112, 2261-2271.

Till, B.G., Jensen, M.C., Wang, J., Qian, X., Gopal, A.K., Maloney, D.G., Lindgren, C.G., Lin, Y., Pagel, J.M., Budde, L.E., Raubitschek, A., Forman, S.J., Greenberg, P.D., Riddell, S.R., and Press, O.W. (2012). CD20-specific adoptive immunotherapy for lymphoma using a chimeric antigen receptor with both CD28 and 4-1BB domains: pilot clinical trial results. Blood 119, 3940-3950.

Wang, Y., Dai, H., Li, H., Lv, H.Y., Wang, T., Fu, X., and Han, W. (2011). Growth of Human colorectal cancer SW1116 cells is inhibited by cytokine-induced killer cells. Clin Dev Immunol 2011, doi: $10.1155 / 2011 / 621414$.

Wolchok, J.D., Hoos, A., O’Day, S., Weber, J.S., Hamid, O., Lebbé, C., Maio, M., Binder, M., Bohnsack, O., Nichol, G., Humphrey, R., and Hodi, F.S. (2009). Guidelines for the evaluation of immune therapy activity in solid tumors: immune-related response criteria. Clin Cancer Res 15, 7412-7420.

Yamada, T., Azuma, K., Muta, E., Kim, J., Suqawara, S., Zhang, G.L., Matsueda, S., Kasama-Kawaguchi, Y., Yamashita, Y., Yamashita, T., Nishio, K., Itoh, K., Hoshino, T., and Sasada, T. (2013). EGFR T790M 
mutation as a possible target for immunotherapy; identification of HLA-A *0201-restricted $\mathrm{T}$ cell epitopes derived from the EGFR T790M mutation. PLoS One 8, e78389.

Zheng, Z., Chinnasamy, N., and Morgan, R.A. (2012). Protein L: a novel reagent for the detection of chimeric antigen receptor (CAR) expression by flow cytometry. J Transl Med 10, 29.

Zhou, X., Li, J., Wang, Z., Chen, Z., Qiu, J., Zhang, Y., Wang, W., Ma, Y., Huang, N., Cui, K., Li, J., and Wei, Y.Q. (2013). Cellular immunotherapy for carcinoma using genetically modified EGFR-specific $\mathrm{T}$ lymphocytes. Neoplasia15, 544-553.

Open Access This article is distributed under the terms of the Creative Commons Attribution License which permits any use, distribution, and reproduction in any medium, provided the original author(s) and source are credited.

\section{SUPPORTING INFORMATION}

Figure S1 CAR expression on T cells of all patients was detected with Protein L. CAR-T cells were incubated with biotinylated protein L (GeneScript, Piscataway, NJ) and phycoerythrin (PE)-conjugated streptavidin (SA, BD Bioscience, San Jose, CA). No-Prot. L indicates that samples stained with SA-PE alone were determined as control. Plots gated on $\mathrm{CD}^{+} \mathrm{T}$ cells. Numbers represent the percentage of $\mathrm{CAR}{ }^{+}$cells.

Figure S2 EGFR expression in A549, MCF7, HeLa and A2780 cells was determined by flow cytometry. These tumor cells were incubated with anti-EGFR primary antibody (Abcam) and goat anti-mouse IgG PE-conjugated antibody (Jackson ImmunoResearch Laboratories). MFI indicates mean fluorescence intensity. Results are representative of three experiments.

Figure S3 The cytokine levels in all patients before and after CAR-T-EGFR cell infusion. Serum was obtained from the peripheral blood of each patient before and at serial time points after CAR-T-EGFR cell infusion. BD Biosciences microbead sandwich immunoassay was used to show the changes in the serum cytokine levels in all patients.

Table S1 Immunohistochemistry Examination of EGFR

Table S2 Phenotypic composition of infused cell products

The supporting information is available online at life.scichina.com and link.springer.com. The supporting materials are published as submitted, without typesetting or editing. The responsibility for scientific accuracy and content remains entirely with the authors. 